\title{
Household food insecurity is associated with self-reported pregravid weight status, gestational weight gain and pregnancy complications
}

\author{
Barbara A. Laraia, PhD., MPH, RD ${ }^{\mathrm{a}}$, Anna Maria Siega-Riz, PhD, RD ${ }^{\mathrm{b}}$, and Craig Gundersen, \\ PhDC

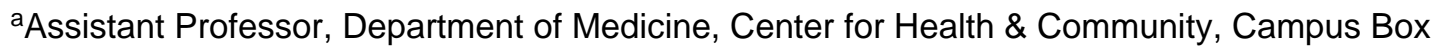 \\ \#0844, University of California, San Francisco, CA 94118. Telephone: (415) 476-7655; Fax: (415) \\ 502-0101; laraiab@chc.ucsf.edu. At the time of this study Dr. Laraia was a Research Assistant \\ Professor at the University of North Carolina and a Fellow at the Carolina Population Center, \\ Chapel Hill, NC. \\ ${ }^{\mathrm{b}}$ Associate Professor, Department of Epidemiology and Nutrition, School of Public Health, \\ Campus Box 7435, University of North Carolina, Chapel Hill, NC 27599. Telephone: (919) \\ 962-8410; am_siegariz@unc.edu. \\ 'Associate Professor, Department of Agricultural and Consumer Economics, University of Illinois, \\ 324 Mumford Hall, 1301 W. Gregory Dr., Urbana, IL 61801. Telephone: 217-333-2857 \\ cggunder@illinois.edu. At the time of this study Dr. Gundersen was an Economist for the USDA \\ Economic Research Services, Washington, DC.
}

\begin{abstract}
Background-Household food insecurity is positively associated with weight among women. The association between household food insecurity and pregnancy related weight gain and complications is not well understood.
\end{abstract}

Objective-To identify if an independent association exists between household food insecurity and pregnancy related complications.

Design-Data from the Pregnancy, Infection and Nutrition prospective cohort study were used to assess household food insecurity retrospectively using the United States Department of Agriculture (USDA) 18-item Core Food Security Module (CFSM) among 810 pregnant women with incomes $\leq 400 \%$ of the income/poverty ratio, recruited between January 2001 and June 2005 and followed through pregnancy.

Main outcome measures-Self-reported pregravid body mass index, gestational weight gain, second trimester anemia, pregnancy-induced hypertension, and gestational diabetes mellitus. Statistical analyses performed: Multivariate linear, multinomial logistic and logistic regression analyses.

(C) 2010 The American Dietetic Association. Published by Elsevier Inc. All rights reserved.

Address correspondence to: Barbara A. Laraia, Ph.D., Center for Health and Community, CB \#0844, The University of California, San Francisco, San Francisco, CA 94118, laraiab@chc.ucsf.edu, Telephone: (415) 476-7655, Fax: (415) 502-0101.

Publisher's Disclaimer: This is a PDF file of an unedited manuscript that has been accepted for publication. As a service to our customers we are providing this early version of the manuscript. The manuscript will undergo copyediting, typesetting, and review of the resulting proof before it is published in its final citable form. Please note that during the production process errors may be discovered which could affect the content, and all legal disclaimers that apply to the journal pertain.

None of the authors have a conflict of interest with a funding source. 
Results-Among 810 pregnant women, $76 \%$ were from fully food secure, $14 \%$ were from marginally food secure, and $10 \%$ were from food insecure households. In adjusted models, living in a food insecure household was significantly associated with severe pregravid obesity [adjusted odds ratio (AOR) 2.97, 95\% confidence intervals (CI) 1.44, 6.14], higher gestational weight gain [adjusted $\beta$ coefficient $1.87,95 \%$ CI $0.13,3.62$ ] and with a higher adequacy of weight gain ratio [adjusted $\beta 0.27$, CI $0.07,0.50$ ]. Marginal food security was significantly associated with gestational diabetes mellitus [AOR 2.76, 95\% CI 1.00, 7.66].

Conclusions-This study highlights the possibility that living in a food insecure household during pregnancy may increase risk of greater weight gain and pregnancy complications.

\section{Keywords}

Food insecurity; pregnancy; weight; obesity; weight gain

\section{INTRODUCTION}

Since 1995, household food insecurity, has been monitored as a public health issue for lowincome households in the United States (US) — operationally defined as "whenever the availability of nutritionally adequate and safe food, or the ability to acquire acceptable foods in socially acceptable ways, is limited or uncertain" (1). In 2007, about $11.9 \%$ of all US households, experienced food insecurity (2). There are a number of factors associated with a household's probability of food insecurity including low-income, being headed by a single mother, the number of children, minority race, asset levels, and psychosocial factors (3-8).

There is some evidence that household food insecurity may be particularly important among women. For example, household food insecurity has been associated with reduced micronutrient intake among women of child-bearing age $(9,10)$ and was associated with a significant decrease in fruit and vegetable consumption, and a significant increase in scores indicative of disordered eating patterns (10). Household food insecurity status is associated with overweight and obesity among women in several (11-18) but not all studies $(19,20)$. In contrast, the association between household food insecurity and overweight status is inconsistent for men (11-13,18-20) and for children (21-27). The significant relationship between household food insecurity and overweight/obesity has been found to be stronger for women of minority ethnicities $(14,15)$ and among women in rural settings (28) compared to non-Hispanic white women.

In addition to weight status, household food insecurity has been associated with compromised psychosocial functioning $(20,28,29)$, poorer mental health $(4,6,30,31)$, and depression $(20,32)$. Household food insecurity may be precisely the type of stress induced exposure that is hypothesized to influence adverse eating behaviors, food choice and increase visceral adiposity (33). Among non-pregnant adults, household food insecurity may both predispose one to and exacerbate the manifestations of diabetes mellitus (34-36). In recent studies, household food insecurity was associated diabetes after controlling for weight status and other potential confounders $(34,35)$. Among adults already diagnosed with diabetes, household food insecurity was further associated with poor diabetes management in a clinic setting (36).

Pregnancy is a time during which women can experience dramatic behavioral, physiologic and psychosocial changes that can have direct implications for both fetal development and future maternal health. Although pregnancy is often viewed as a period of a woman's life that may lead to improved health behaviors, over $40 \%$ of women begin pregnancy as overweight or obese (37). Pregravid overweight is associated with poor dietary intake $(38,39)$ and excessive weight gain $(40-45)$, as well as gestational diabetes mellitus $(46,47)$, 
pre-eclampsia (48), pregnancy induced hypertension (49), and postpartum anemia (50,51). Many of these conditions may be exacerbated by living within a food insecure household during pregnancy.

Household food insecurity was hypothesized for this study as an exposure, predisposing women to gain excessive weight during adulthood. Therefore, a positive association was predicted between household food insecurity and pregravid weight status. Exposure to household food insecurity was also predicted to be associated with excessive gestational weight gain since pregnancy is a period of actual and perceived increase in food need. Furthermore, household food insecurity was hypothesized to be associated with pregnancy complications (See Figure 1). More specifically, the purpose of this study was to investigate the association between household food insecurity status and pregravid body mass index (BMI), gestational weight gain, pregnancy-induced hypertension (PIH), anemia and gestational diabetes mellitus (GDM) among pregnant women.

\section{MATERIALS AND METHODS}

\section{Study Sample}

This study used data from the Pregnancy, Infection, and Nutrition (PIN) cohort, a prospective study that examined the influence of several socio-behavioral and medical factors on the risk of preterm birth. Between January 2001 and June 2005, 2006 pregnant women were recruited through the University of North Carolina Hospitals residents and private physician obstetrics clinics before 20 weeks' gestation and followed through their pregnancy. Women completed a telephone interview between 27 and 30 weeks' gestation that included demographic and socioeconomic status, health behaviors, physical activity and a retrospective measure of household food security status. Full details are published elsewhere (4). Pregnant women were excluded from these analyses if they had incomplete household food security status and delivery information $(n=337)$. From the 1669 pregnant women who completed the study and had complete information on household food security status, the analyses were limited to pregnant women from households with incomes at or below $400 \%$ of the income/poverty ratio $(n=810)$. The household income restriction allowed better comparison among households that might have food insecurity due to financial and material constraints and purposefully excluded any households with higher incomes. The PIN study was app roved by and its procedures were in accordance with the ethical standards of the Institutional Review Board of the University of North Carolina School of Medicine.

\section{Food Insecurity-Main Exposure}

Household food insecurity status was assessed between 27 and 30 weeks' gestation using the 18-item CFSM administered via telephone (2). Questions were asked pertaining to all individuals' experience of food insecurity over the past 12 months who lived within the same household. Examples include "I worried whether our food would run out before we got money to buy more," (the least severe question); "Did you or the other adults in your household ever cut the size of your meals or skip meals because there wasn't enough money for food;" "Did you or other adults in your household ever not eat for a whole day because there wasn't enough money for food?;" and "Did a child in the household ever not eat for a full day because you couldn't afford enough food" (the most severe question). Household food insecurity status appeared to be a stable estimate over the past 12 months in this sample as evidenced by two questions that were broken into two time segments, in addition to the general question for the past 12 months, pertaining to the six months before pregnancy and the six months during pregnancy. The same $5 \%$ of women $(n=37)$ who reported that adults in the household needed to cut the size of a meal or skip a meal any time in the past 12 
months, reported that this occurred between one to four months before pregnancy as well as one to four months during pregnancy. Additionally, the same $0.5 \%$ of women $(n=4)$ who reported that adults in the household went a whole day without food any time in the past 12 months, reported that this occurred between one to three months before pregnancy and two to three months during pregnancy. A household was classified as (a) food secure if the respondent answered "no" to all 18-items; as (b) marginally food secure if the respondent answered in the affirmative to one or two questions indicating that there was anxiety about sufficient quantity of food; and as (c) food insecure if the respondent answered in the affirmative to three or more questions indicating insufficient quantity and reduced quality and desirability of food (2). A three level household food security variable was created to estimate the association between household food insecurity status over the last 12 months and the outcomes.

\section{Heath Outcomes}

Self reported pre-pregnancy weight and measured height were used to construct pregravid body mass index $\left(\mathrm{BMI}, \mathrm{kg} / \mathrm{m}^{2}\right)$. Recalled pre-pregnancy weight is shown to correlate well with measured weights (52). For 7\% ( $\mathrm{n}=58)$ of the analysis sample, an imputed weight was used in lieu of the self-reported measure only when it was missing or considered biologically implausible. This imputed weight used the measured weight at the first prenatal visit (if taken prior to 16 weeks) minus the recommended amount of weight to be gained in the first and second trimesters as defined by the Institute of Medicine (IOM) (53). If the first weight measurement was after 15 weeks of gestation, a pre-pregnancy weight could not be imputed. The majority of imputed weights ( $72 \%$ ) were for women from food secure households; however, the proportion of imputed BMI values was not significantly different by food security category. This methodology has been previously used in other studies $(54,55)$. Weight status categories for this analysis were defined using the IOM BMI cut points for pregnant women as follows: $<19.8 \mathrm{~kg} / \mathrm{m}^{2}$ (underweight), $19.8-26.0 \mathrm{~kg} / \mathrm{m}^{2}$ (normal), >26- $29.0 \mathrm{~kg} / \mathrm{m}^{2}$ (overweight), >29-35.0 kg/m (obese) (56) and $\geq 35 \mathrm{~kg} / \mathrm{m}^{2}$ (severe obesity) (57). The IOM cut points were used because gestational weight gain recommendations are based on these categories. Gestational weight gain was measured three ways. First, total gestational weight gain was measured in kilograms. Second, an adequacy of gestational weight gain ratio was created, and third, a categorical variable was created using the IOM weight gain recommendations. Gestational weight gain was calculated as the difference between each woman's self-reported pregravid weight and her weight measured near the time of delivery. This variable took into consideration the gestational age at the last weight measurement $(55,58,59)$. The continuous variable, adequacy of gestational weight gain ratio was calculated according to pregravid BMI status, and was a ratio of observed total weight gain over expected weight gain up until the last prenatal visit using the weight gain recommendations from the 1990 IOM report as previously described $(51,55,58)$. Expected weight gain was calculated using the following formula: expected first-trimester total weight gain $+[$ (gestational age at time of last weight measurement $-13 \mathrm{wk}) \times$ rate of weight gain expected for the second and third trimesters]. The expected total first-trimester weight gains were $3.2,2.2,1.0$, and $0.5 \mathrm{~kg}$, and the rates were $0.5,0.4,0.3$, and $0.2 \mathrm{~kg} / \mathrm{wk}$ for underweight, normal-weight, overweight, and obese women, respectively (53). These rates adjusted for the observation that not all women have a weight measurement at the time of delivery. For example, it is recommended that an overweight women gain between 7.0 and $11.5 \mathrm{~kg}$, which corresponds to a ratio of $80 \%$ to $120 \%$ if the pregnancy is carried to term (40 wk). Therefore, a ratio $>1.20$ would be defined as gaining above the IOM recommendation (excessive) and those who have a ratio $<0.80$ would be defined as gaining below the IOM recommendation (inadequate). Adequacy of gestational weight gain was then categorized to determine inadequate and excessive weight gains again based on the IOM BMI-specific recommendations (53). 
Pregnancy complications including pregnancy-induced hypertension (PIH), second trimester anemia and gestational diabetes mellitus (GDM) were abstracted from medical charts and constructed as dichotomous variables. Trained research staff conducted systematic medical chart abstraction after delivery using a computer-assisted program with internal edit checks. PIH was defined as "a systolic blood pressure level of $140 \mathrm{~mm}$ hg or higher or a diastolic blood pressure level of $90 \mathrm{~mm}$ hg or higher that occurs after 20 weeks of gestation in a woman with previously normal blood pressure" (60). Using this definition, roughly $20 \%$ of the study sample was anticipated to meet the criteria for PIH. Universal screening protocols for identifying GDM were used in the UNC prenatal clinics $(47,61)$. GDM was based on medical chart abstraction of glucose tolerance information from universal glucose screening between 24 and 29 weeks' gestation. An oral glucose tolerance test (OGTT) was administered in fasting state on serum samples using a glucose oxidase method with glucose tolerance analysis at fasting, and at 1,2, and 3 hours after the oral glucose load. GDM was defined as having two or more abnormal values from an oral glucose tolerance test. Second trimester anemia was defined as $\mathrm{Hgb}<10.5 \mathrm{~g} / \mathrm{dl}$ per Centers for Disease Control and Prevention definitions of anemia for pregnancy (62).

\section{Statistical Methods}

Descriptive analysis was performed to examine the association between the trichotomous household food security variable and each potential covariate using one-way analysis of variance with Bonferroni multiple-comparison test for the continuous variables of age, number of children, percent of income/poverty ratio and total metabolic equivalents hours per week of any physical activity, and the outcomes of kilograms of weight gain and adequacy of weight gain ratio. Self-reported physical activity was converted into metabolic equivalent of task (MET) hours using a standardized approach and a summary MET hours/ week was calculated combining the total MET hours/week for each activity domain $(65,66)$. Physical activity was assessed over a one week recall period using a nine-item questionnaire that included the domains of: work, recreational, household activities, and transportation with probes for type, frequency, duration and intensity (64). A $\chi^{2}$ tests was used for the categorical covariates of maternal race (indicator for black compared with white and other), marital status (indicator for single compared with married), maternal education (indicator for less than 12 years, 12 years, some college compared with college or more), smoking (indicator for any smoking during the first 6 months of pregnancy compared with none), and BMI category (normal weight as the indicator), and outcome variables of pregnancy-induced hypertension, anemia and gestational diabetes mellitus.

Odds ratios were used for low prevalence outcomes ( $\leq 15 \%$ occurrence) as they can approximate risk ratios. Multinomial logistic regression models were used to estimate the association between household food insecurity status and BMI category, and logistic regression models were used to estimate the association between household food insecurity status and anemia and GDM. Linear regression models were used to estimate the association between household food insecurity status and the continuous outcome of kilograms of weight gained and adequacy of gestational weight gain ratio. Incident risk ratios were calculated using poisson regression with robust variance estimators to estimate common outcomes (> 15\% occurrence) for the association between household food insecurity status and gestational weight gain as well as PIH (63). Adjusted models controlled for all of the covariates listed above. Gestational age was an additional covariate in the model estimating kilograms of weight gained. Models estimating the association between household food insecurity status and pregnancy complications did not adjust for gestational weight gain because a measure for gestational weight gain prior to diagnosis was needed but only total gestational weight gain was available for this analysis. Controlling for total gestational weight gain would be inappropriate since the pregnancy complications once diagnosed can 
be related to gestational weight gain as in the case of gestational diabetes mellitus or can be part a consequence of the condition as is the case in pregnancy induced hypertension or preeclampsia (67). Stata software was used for data management and statistical calculations (StataCorp. Stata statistical software: release 9.0. College Station (TX): Stata Corporation; 2003).

\section{RESULTS}

\section{Characteristics of the study population by household food insecurity status}

The general characteristics of this population have been previously reported (4). Women who met the inclusion criteria but who were excluded from the analysis due to missing information had a lower mean age (26.8 vs. 29.2 years), mean education (13.6 vs. 15.6 years), mean income ( 2.52 vs. 4.08 income/poverty ratio), respectively, and a higher proportion were black. Roughly, $76 \%$ of the sample were from food secure households, while $24 \%$ were from marginally food secure and $10 \%$ were from food insecure households. Overall, women from marginally food secure and food insecure households were similar with regard to most demographic, socioeconomic and weight status variables assessed in this study. Compared to women from food secure households, women from marginally secure and food insecure households were significantly more likely to be black, to be single, have less years of education, less income and be either overweight or severely obese (Table 1).

\section{Association between pregravid BMI status and household food insecurity status}

The prevalence of pregravid BMI was $13 \%$ underweight, $42 \%$ normal weight, $12 \%$ overweight, $17 \%$ obese, and $16 \%$ severely obese. In unadjusted models, women living in households with either marginal food security or food insecurity were associated with severe obesity (Table 2). In adjusted models, women from a food insecure household were associated with almost three times the odds of severe obesity compared to normal weight women, after controlling for covariates age, race, income, education, marital status and number of children.

\section{Association between household food insecurity status and gestational weight gain}

The extent of association between living in a food insecure household and gestational weight gain was estimated in three ways. First, in adjusted models, a significant association was found between living in a food insecure household and kilograms of weight gained after adjusting for age, race, income, education, marital status, number of children, smoking, physical activity, gestational age and pregravid BMI (Table 3). On average, women from food insecure households gained 1.87 kilograms, or 4 pounds, more than women from food secure household (adjusted $\beta 1.87,95 \%$ confidence intervals $0.13,3.62$ ). Second, women from food insecure households were significantly associated with higher adequacy of gestational weight gain ratio; an indicator of excessive weight gain, (adjusted $\beta 0.27,95 \%$ confidence intervals $0.03,0.50$ ) after adjusting for age, race, income, education, marital status, number of children, smoking, physical activity and pregravid BMI. Living in a marginally food secure household was not associated with either kilograms of weight gain or adequacy of weight gain ratio. Third, multinomial logistic regression models were used to assess the association between categories of adequacy of weight gain (inadequate and excessive compared with adequate weight gain) and living in a food insecure household but no association was found between household food insecurity status and either inadequate or excessive weight gain in adjusted models (data not shown). Therefore, although pregnant women from households experiencing food insecurity had significantly higher weight gain and a significantly higher adequacy of weight gain ratio, they were not at greater relative risk of falling into the excessive weight gain category compared with women from food secure households. 


\section{Association between household food insecurity status and pregnancy complications}

Finally, the extent of association was estimated between household food insecurity status and pregnancy complications. In unadjusted models, women from marginally food secure households were associated with second trimester anemia and GDM, while women from food insecure households were associated with PIH (Table 4). However, in adjusted models, women from food insecure households were no longer associated with PIH, and women from marginally food secure households were no longer associated with second trimester anemia. The estimated association between women living in marginally food secure households and GDM remained greater than two fold after adjusting for age, race, maternal education, marital status, children, the income/poverty ratio, pregravid BMI, physical activity and smoking status. The estimates for the association between household food insecurity and GDM were similar to that of marginal food insecurity; however, the confidence interval was wide. Using a combined marginal/food insecure household category the association with GDM was estimated and a higher odds ratio resulted (OR 2.38, 95\% CI: $0.99,5.73$ ) and was significant at $\mathrm{p} \leq 0.05$, suggesting that women living in a household with any level of food insecurity may be associated with GDM.

\section{DISCUSSION}

Household food insecurity - the inability to obtain nutritious and safe foods in socially acceptable ways - is increasingly recognized as an independent risk factor for many poor health outcomes among women. Studies have shown that household food security and weight status can have a paradoxical relationship_-with women living in food insecure households reporting higher prevalence rates of overweight (11-18) and related health complications (34-36). The present study was conducted to estimate the association between household food insecurity status and maternal health during pregnancy, when changes in both body weight and overall health can be dramatic. The results suggest that the experience of living in a food insecure household was associated with metabolic health indicators during pregnancy. Not only was living in a food insecure household associated with severe pregravid obesity - a condition that broadly predisposes women to adverse pregnancy outcomes-but also with greater weight gain and gestational diabetes mellitus.

The results of this study identified an observed relationship between household food insecurity and pregravid severe obesity. The finding of an association between household food insecurity and higher BMI has been observed among non-pregnant women, but a graduated relationship has not been previously documented (11-18). Being severely obese was associated with three times greater odds of reporting household food insecurity in adjusted analyses. Several other studies (11-18) have shown a consistent, significant relationship between household food insecurity and weight status among women, but only a few have shown evidence of a relationship between the experience of household food insecurity and actual weight gain $(11,68)$. One study found no relationship with weight gain (69). Olson et al., found that among pregnant women in rural upstate New York pregravid obesity was associated with becoming food insecure during the postpartum period (70). In this study, pregnant women from food insecure households had significantly higher weight gain and a higher adequacy of weight gain ratio, compared with women from food secure households. However, living in a food insecure households was not associated with higher odds of excessive weight gain.

Household food insecurity may increase consumption of highly palatable foods through a stress-mediated pathway and/or through an economic dependence on inexpensive, calorie dense foods. Household food insecurity was previously found to be associated with several measures of psychosocial factors (4). When access to food is limited, it is hypothesized that women may rely on less expensive foods that are nutrient poor and calorie-rich (71); several 
studies have further speculated that early life exposure to household food insecurity may drive long term weight gain trajectories throughout life-possibly by food hording or dependence on high calorie dense foods $(14,67,72)$. A previous study found that increased pregravid BMI was associated with poor diet quality (38). It is also possible that stress may synergize with the specific effect of household food insecurity on food selection, since eating highly palatable, highly gratifying but low quality foods can also be a response to stress (33). If exposure to household food insecurity mainly influences women's eating behaviors by increasing intake of highly palatable, high calorie dense foods, then one would expect higher gestational weight gains. Additionally, household food insecurity may be associated with decreased physical activity, although no research studies were identified to support this hypothesis. Decreased physical activity may be associated with household food insecurity status if decreased calorie consumption leads to an energy conservation state, however, MET hours/week was used in the model as a covariate and did not attenuate the association between household food insecurity and any outcome. Furthermore, stress associated with household food insecurity also may be associated with decreased physical activity. On average, less than $40 \%$ of pregnant women have been found to meet physical activity guidelines and levels of physical activity often decreases as pregnancy progresses (64).

Since the real demand for food, appetite, and stress can all increase during pregnancy, the influences of household food insecurity on health outcomes during pregnancy are an important concern. For this study, it was hypothesized that household food insecurity would be associated with three diet and weight associated pregnancy complications; PIH, second trimester anemia and GDM. The null finding for the relationships between household food insecurity, PIH and anemia may be because dietary and weight status are not strong influences on PIH and anemia. For instance, pregnancy related anemia may be more influenced by hemodilution, undernutrition, nausea/vomiting and a lack of iron supplement use (51). Although the etiology of PIH is believed to be influenced by metabolic abnormalities and possibly pregravid obesity, PIH may be less influenced by diet and more influenced by excessive pregnancy weight gain or another etiology (73). The significant finding between household food insecurity and GDM, independent of self-reported pregravid weight status is an important public health finding given that GDM has implications for both the fetus (e.g., macrosomia) as well as the mother (e.g., a significant precursor to type II diabetes later in life). The association between household food insecurity and GDM may be mediated through poor health behaviors and poor dietary intake during pregnancy such as a high fat intake (61).

Limitations of this study include the 337 women excluded from the analysis due to missing information who had significantly less education, less income and were more likely to be black, which are all risk factors for household food insecurity. Therefore, the exclusion of these women may have biased the findings to the null hypothesis of no association between household food insecurity and the assessed pregnancy complication. The analysis of the association between self-reported pregravid weight status and household food insecurity status for this study is cross-sectional and the observational nature of this study does not allow for causal relationships to be made, however, the temporal nature of weight gain and maternal complications coming after the reporting of household food insecurity suggests that household food insecurity may be an antecedent for these conditions. Further studies will need to be conducted on a representative sample of women from various ethnic backgrounds to confirm these findings. Also, the small sample size may have affected the lack of significant finding in the adjusted models. With only $10 \%$ ( $\mathrm{n}=79$ women) experiencing household food insecurity, combined with the large number of covariates, the sample size constraints likely affected the statistical power to detect significant associations. And finally, self-reported weight was used to calculate pregravid BMI. There are several studies that 
suggest self-report correlates well with actual weight, and all weights in this study were checked for biologic plausibility of the self-reported weight with the first prenatal visit measured weight if it occurred before 15 weeks and corrected it if deemed implausible. However, self-reported weight is problematic since the adequacy of gestational weight gain outcome variables were based on pregravid BMI. For example, a weight gain of 30 pounds would be adequate for a normal weight woman (weight gain recommendation is between 25-35 pounds) but would excessive for an overweight woman (weight gain recommendation is between 15-25 pounds). If an overweight woman underreported her pregravid weight to the extent that she was classified as being within the normal pregravid BMI category, the 30 pound weight gain would be classified as adequate biasing the findings to the null hypothesis of no association with household food insecurity status.

\section{CONCLUSION}

In an analysis that controlled for a wide variety of socioeconomic and demographic covariates, the experience of household food insecurity was significantly, and independently, associated with being severely obese prior to pregnancy; with having higher weight during pregnancy compared with women from food secure households; and with developing gestational diabetes mellitus. This study emphasizes that a pregnant woman who also experienced household food insecurity may be at greater risk of complications of pregnancy. The results strongly support the recommendation that obese women should be targeted for tailored nutritional counseling and intervention which also includes the assessment of household food insecurity. Furthermore, assessing household food insecurity status could be particularly useful for obese pregnant women-for whom a positive association with household food insecurity has been found and living in a food insecure household is potentially more consequential than non-obese pregnant women. Public health efforts must continue to provide adequate funding and outreach to those in need, and population-based programs and policies must aim to ensure that pregnant women have access to high-quality, nutritious food.

\section{Acknowledgments}

This study was supported by the United States Department of Agriculture, Economic Research Service grant 43-3AEM-0-80086, entitled "Effects of Food Security on Pregnancy Outcomes"; and by grants HD28684 from the National Institute of Child Health and Human Development, National Institutes of Health; funding from the National Institutes of Health, General Clinical Research Centers program of the Division of Research Resources (grant \# RR00046).

\section{References}

1. Anderson SA. Core Indicators of Nutritional State for Difficult-to-Sample Populations. J Nutr 1990;120:1559S-1600S.

2. Nord, M.; Andrews, M.; Carlson, S. Household Food Security in the United States, 2007. Washington, DC: US Department of Agriculture; 2008. Economic Research Report 66

3. Gundersen C. Measuring the extent, depth, and severity of food insecurity: An application to American Indians in the United States. J Pop Econ 2008;21:191-215.

4. Laraia BA, Siega-Riz AM, Gundersen C, Dole N. Psychosocial factors and socioeconomic indicators are associated with household food insecurity among pregnant women. J Nutr 2006;136:177-182. [PubMed: 16365079]

5. Dunifon R, Kowaleski-Jones L. The influences of participation in the National School Lunch Program and food insecurity on child well-being. Soc Serv Rev 2003;77:72-92.

6. Gundersen C, Weinreb L, Wehler C, Hosmer D. Homelessness and food insecurity. J Housing Econ 2003;12:250-272. 
7. Evenson KR, Laraia BA, Welch VL, Perry AL. Statewide prevalences of concern about enough food. Public Health Rep 2002;117:358-365. [PubMed: 12477917]

8. Gundersen C, Oliveira V. The Food Stamp Program and food insufficiency. Am J Ag Econ 2001;84:875-887.

9. Rose D, Oliveira V. Nutrient intakes of individuals from food-insufficient households in the United States. Am J Pub Health 1997;87:1856-1861.

10. Kendall A, Olson CM, Frongillo EA. Relationship of hunger and food insecurity to food availability and consumption. J Am Diet Assoc 1996;96:1019-1024. [PubMed: 8841164]

11. Holben DH, Pheley AM. Diabetes risk and obesity in food-insecure households rural Appalachian Ohio. Prev Chronic Dis 2006;3:1-9.

12. Martin K, Ferris A. Food Insecurity and Gender are Risk Factors for Obesity. J Nutr Ed Behav 2006;39:31-36.

13. Wilde PE, Peterman JN. Individual weight change is associated with household food security status. J Nutr 2006;136:1395-1400. [PubMed: 16614436]

14. Kaiser L, Townsend M, Melgar-Quinoñez H, Fujii M, Crawford P. Choice of instrument influences relations between food insecurity and obesity in Latino women. Am J Clin Nutr 2004;80:13721378. [PubMed: 15531689]

15. Adams E, Grummer-Strawn L, Chavez G. Food insecurity is associated with increased risk of obesity in California women. J Nutr 2003;133:1070-1074. [PubMed: 12672921]

16. Basiotis PP, Lino M. Insight 26: Food insufficiency and prevalence of overweight among adult women. Family Economics and Nutrition Review 2003;15:55-57.

17. Sarlio-Lahteenkorva S, Lahelma E. Food insecurity is associated with past and present economic disadvantage and body mass index. J Nutr 2001;131:2880-2884. [PubMed: 11694612]

18. Townsend MS, Peerson J, Love B, Achterberg C, Murphy SP. Food insecurity is positively related to overweight in women. J Nutr 2001;131:1738-1745. [PubMed: 11385061]

19. Laraia BA, Siega-Riz AM, Evenson KR. Self-reported overweight and obesity are not associated with concern about enough food among adults in New York and Louisiana. Prev Med 2004;38:175-181. [PubMed: 14715209]

20. Vozoris N, Tarasuk V. Household Food Insufficiency is associated with Poorer Health. J Nutr 2003;133:120-126. [PubMed: 12514278]

21. Casey PH, Simpson PM, Gossett JM, Bogle ML, Champagne CM, Connell C, Harsha D, McCabeSellers B, Robbins JM, Stuff JE, Weber J. The association of child and household food insecurity with childhood overweight status. Pediatrics 2006;118:e1406-e1413. [PubMed: 17079542]

22. Jones SJ, Jahns L, Laraia BA, Haughton B. Lower risk of overweight in school-aged food insecure girls who participate in food assistance: results from the panel study of income dynamics child development supplement. Arch Pediatr Adolesc Med 2003;157:780-784. [PubMed: 12912784]

23. Alaimo K, Olson CM, Frongillo EA. Low family income and food insufficiency in relation to overweight in US children: is there a paradox? Arch Pediatr Adolesc Med 2001;155:1161-1167. [PubMed: 11576013]

24. Casey P, Szeto K, Lensing S, Bogle M, Weber J. Children in food-insufficient, low-income families: Prevalence, health and nutrition status. Arch Pediatr Adolesc Med 2001;155:508-514. [PubMed: 11296080]

25. Gundersen C, Lohman B, Eisenmann J, Garasky S, Stewart S. Lack of association between childspecific food insecurity and overweight in a sample of 10-15 year old low-income youth. J Nutr 2008;138:371-378. [PubMed: 18203906]

26. Gundersen C, Lohman B, Garasky S, Stewart S, CEisenmann J. Food security, maternal stressors, and overweight among low-income U.S. children: Results from NHANES 1999-2002. Pediatrics 2008;122:e529-e540. [PubMed: 18762488]

27. Gundersen C, Garasky S, Lohman B. Food insecurity is not associated with childhood obesity as assessed using multiple measures of obesity. J Nutr 2009;139:1173-1178. [PubMed: 19403713]

28. Olson CM. Nutrition and health outcomes associated with food insecurity and hunger. J Nutr 1999;129:512S-524S. 
29. Kleinman RE, Murphy JM, Little M, Pagano M, Wehler CA, Regal K, Jellinek MS. Hunger in children in the United States: potential behavioral and emotional correlates. Pediatrics 1998;101:e3. [PubMed: 9417167]

30. Casey P, Goolsby S, Berkowitz C, Frank D, Cook J, Cutts D, Black MM, Zaldivar N, Levenson S, Heeren T, Meyers A. Children's Sentinel Nutritional Assessment Program Study Group. Maternal depression, changing public assistance, food security, and child health status. Pediatrics 2004;113:298-304. [PubMed: 14754941]

31. Stuff JE, Casey PH, Szeto KL, Gossett JM, Robbins JM, Simpson PM, Connell C, Bogle ML. Household food insecurity is associated with adult health status. J Nutr 2004;134:2330-2335. [PubMed: 15333724]

32. Che J, Chen J. Food insecurity in Canadian households. Health Reports 2002;12:11-21. [PubMed: 15069808]

33. Adam TC, Epel ES. Stress, eating and the reward system. Physiol Behav 2007;91:449-458. [PubMed: 17543357]

34. Seligman HK, Bindman AB, Vittinghoff E, Kanaya AM, Kushel MB. Food insecurity is associated with diabetes mellitus: results from the National Health Examination and Nutrition Examination Survey (NHANES) 1999-2002. J Gen Intern Med 2007;22:1018-1023. [PubMed: 17436030]

35. Maddigan SL, Feeny DH, Majumdar SR, Farris KB, Johnson JA. Understanding the determinants of health for people with type 2 diabetes. Am J Public Health 2006;96:1649-1655. [PubMed: 16873750]

36. Nelson K, Cunningham W, Andersen R, Harrison G, Gelberg L. Is food insufficiency associated with health status and health care utilization among adults with diabetes? J Gen Intern Med 2001;16:404-411. [PubMed: 11422638]

37. Yeh J, Shelton JA. Increasing prepregnancy body mass index: analysis of trends and contributing variables. Am J Obstet Gynecol 2005;193:1994-1998. [PubMed: 16325602]

38. Laraia BA, Bodnar LM, Siega-Riz AM. Pregravid body mass index is negatively associated with diet quality during pregnancy. Public Health Nutr 2007;10:920-926. [PubMed: 17381955]

39. Derbyshire E, Davies J, Costarelli V, Dettmar P. Prepregnancy body mass index and dietary intake in the first trimester of pregnancy. J Hum Nutr Diet 2006;19:267-273. [PubMed: 16911239]

40. Wells CS, Schwalberg R, Noonan G, Gabor VG. Factors influencing inadequate and excessive weight in pregnancy: Colorado, 200-2002. Matern Child Health J 2006;10:55-62. [PubMed: 16496222]

41. Brawarsky P, Stotland NE, Jackson RA, Fuentes-Afflick E, Escobar GJ, Rubashkin N, Haas JS. Pre-pregnancy and pregnancy-related factors and the risk of excessive or inadequate gestational weight gain. Strengthening public health priority-setting through research on fistula, maternal health, and health inequities. Int J Gynaecol Obstet 2005;91:125-131. [PubMed: 16202415]

42. Olson CM, Strawderman MS. Modifiable behavioral factors in a biopsychosocial model predict inadequate and excessive gestational weight gain. J Am Diet Assoc 2003;103:48-54. [PubMed: 12525793]

43. Lederman SA, Alfasi G, Deckelbaum RJ. Pregnancy-associated obesity in black women in New York City. Matern Child Health J 2002;6:37-42. [PubMed: 11926252]

44. Caulfield LE, Witter FR, Stoltzfus RJ. Determinants of gestational weight gain outside the recommended ranges among black and white women. Obstet Gynecol 1996;87:760-766. [PubMed: 8677082]

45. Parker JD, Abrams B. Differences in postpartum weight retention between black and white mothers. Obstet Gynecol 1993;81:768-774. [PubMed: 8469470]

46. Solomon CG, Willett WC, Carey VJ, Rich-Edwards J, Hunter DJ, Colditz GA, Stampfer MJ, Speizer FE, Spiegelman D, Manson JE. A prospective study of pregravid determinants of gestational diabetes mellitus. JAMA 1997;278:1078-1083. [PubMed: 9315766]

47. Saldana TM, Siega-Riz AM, Adair LS, Suchindran C. The relationship between pregnancy weight gain and glucose tolerance status among black and white women in central North Carolina. Am J Obstet Gynecol 2006;195:1629-1635. [PubMed: 16824460]

48. Bodnar LM, Ness RB, Markovic N, Roberts JM. The risk of preeclampsia rises with increasing prepregnancy body mass index. Ann Epidemiol 2005;15:475-482. [PubMed: 16029839] 
49. Thadhani R, Stampfer MJ, Hunter DJ, Manson JE, Solomon CG, Curhan GC. High body mass index and hypercholesterolemia: Risk of hypertensive disorders of pregnancy. Obstet Gynecol 1999;94:543-550. [PubMed: 10511356]

50. Bodnar LM, Siega-Riz AM, Cogswell ME. High prepregnancy BMI increases the risk of postpartum anemia. Obesity Research 2004;12:941-948. [PubMed: 15229333]

51. Bodnar LM, Siega-Riz AM, Arab L, Chantala K, McDonald T. Predictors of pregnancy and postpartum haemoglobin concentrations in low-income women. Public Health Nutr 2004; 7:701711. [PubMed: 15369607]

52. Stevens-Simon C, Roghmann K, Mcanarney E. Relationship of self-reported prepregnant weight and weight gain during pregnancy to maternal body habitus and age. J Am Diet Assoc 1992;92:85-87. [PubMed: 1728630]

53. Subcommittee on Nutritional Status and Weight Gain During Pregnancy. Energy requirements, energy intake, and associated weight gain during pregnancy. In: Institute of Medicine., editor. Nutrition during Pregnancy. Part I, Weight Gain. Washington, DC: National Academy Press; 1990. p. 137-175.

54. Siega-Riz AM, Adair LS, Hobel CJ. Maternal underweight status and inadequate rate of weight gain in the third trimester of pregnancy increases the risk of preterm delivery. J Nutr 1996;126:146-153. [PubMed: 8558295]

55. Siega-Riz AM, Adair LS, Hobel CJ. Institute of Medicine maternal weight gain recommendations and pregnancy outcome in a predominantly Hispanic population. Obstet Gynecol 1994;84:565573. [PubMed: 8090394]

56. Institute of Medicine. Nutrition During Pregnancy and Lactation: Am Implementation Guide. Washington, DC: National Academy Press; 1992. Committee on Nutritional Status during Pregnancy and Lactation. Food and Nutrition Board, Subcommittee for Clinical Application Guide.

57. U.S. Department of Health and Human Services, Public Health Service, National Institutes of Health National Heart, Lung, and Blood Institute; 1998 Sep. Clinical Guidelines on the Identification, Evaluation, and Treatment of Overweight and Obesity in Adults--Executive Summary Clinical Guidelines. NIH Publication No. 98-4083

58. Vahratian A, Zhang J, Troendle J, Savitz D, Siega-Riz AM. Maternal pre-pregnancy overweight and obesity and the pattern of labor progression in term nulliparous women. Obstet Gynecol 2004;104:943-951. [PubMed: 15516383]

59. Bodnar LM, Siega-Riz AM. A Diet Quality Index for Pregnancy captures variation in diet and differences in sociodemographic characteristics. Public Health Nutr 2002;5:801-809. [PubMed: 12570888]

60. American College of Obstetricians and Gynecologists (ACOG). Diagnosis and management of preeclampsia and eclampsia. ACOG Bulletin 2002;99(No. 33)

61. Saldana TM, Siega-Riz AM, Adair LS. Effect of macronutrient intake on the development of glucose intolerance during pregnancy. Am J Clin Nutr 2004;79:479-486. [PubMed: 14985225]

62. Center for Disease Control and Prevention. Recommendations to Prevent and Control Iron Deficiency in the United States. MMWR Recomm Rep 1998;47:1-36.

63. Zou G. A modified poisson regression approach to prospective studies with binary data. Am J Epidemiol 2004;159:702-706. [PubMed: 15033648]

64. Borodulin KM, Evenson KR, Wen F, Herring AH, Benson AM. Physical Activity Patterns during Pregnancy. Med Sci Sports Exerc 2008;40:1901-1908. [PubMed: 18845974]

65. Ainsworth BE, Haskell WL, Whitt MC, Irwin ML, Swartz AM, Strath SJ, O'Brien WL, Bassett DR Jr, Schmitz KH, Emplaincourt PO, Jacobs DR Jr, Leon AS. Compendium of physical activities: an update of activity codes and MET intensities. Med Sci Sports Exerc 2000;32:498S-504S.

66. Ainsworth BE, Leon AS, Richardson MT, Jacobs DR, Paffenbarger RS Jr. Accuracy of the College Alumnus Physical Activity Questionnaire. J Clin Epidemiol 1993;46:1403-1411. [PubMed: 8263567]

67. Viswanathan, M.; Siega-Riz, AM.; Moos, M-K.; Deierlein, A.; Mumford, S.; Knaack, J.; Thieda, P.; Lux, LJ.; Lohr, KN. Rockville, MD: Agency for Healthcare Research and Quality; 2008. Outcomes of Maternal Weight Gain, Evidence Report/Technology Assessment No. 168. (Prepared 
by RTI International-University of North Carolina Evidence-based Practice Center under contract No. 290-02-0016.). AHRQ Publication No. 08-E-09

68. Wilde PE, Peterman JN. Individual weight change is associated with household food security status. J Nutr 2006;136:1395-1400. [PubMed: 16614436]

69. Jones SJ, Frongillo EA. Food insecurity and subsequent weight gain in women. Public Health Nutr 2007;10:145-151. [PubMed: 17261223]

70. Olson CM, Strawderman MS. The relationship between food insecurity and obesity in rural childbearing women. J Rural Health 2008;24:60-66. [PubMed: 18257872]

71. Drewnowski A, Darmon N. The economics of obesity: dietary energy density and energy cost. Am J Clin Nutr 2005;82:265S-273S. [PubMed: 16002835]

72. Allen MW, Wilson M. Materialism and food security. Appetite 2005;45:314-323. [PubMed: 16171902]

73. Samuels-Kalow ME, Funai EF, Buhimschi C, Norwitz E, Perrin M, Calderon-Margalit R, Deutsch L, Paltiel O, Friedlander Y, Manor O, Harlap S. Prepregnancy body mass index, hypertensive disorders of pregnancy, and long-term maternal mortality. Am J Obstet Gynecol 2007;197:490.e1490.e6. [PubMed: 17714679] 




Figure 1.

Conceptual Framework of the influence of food insecurity status on gestational weight gain and pregnancy complications

a Pregnancy-Induced Hypertension

b Gestational Diabetes Mellitus 


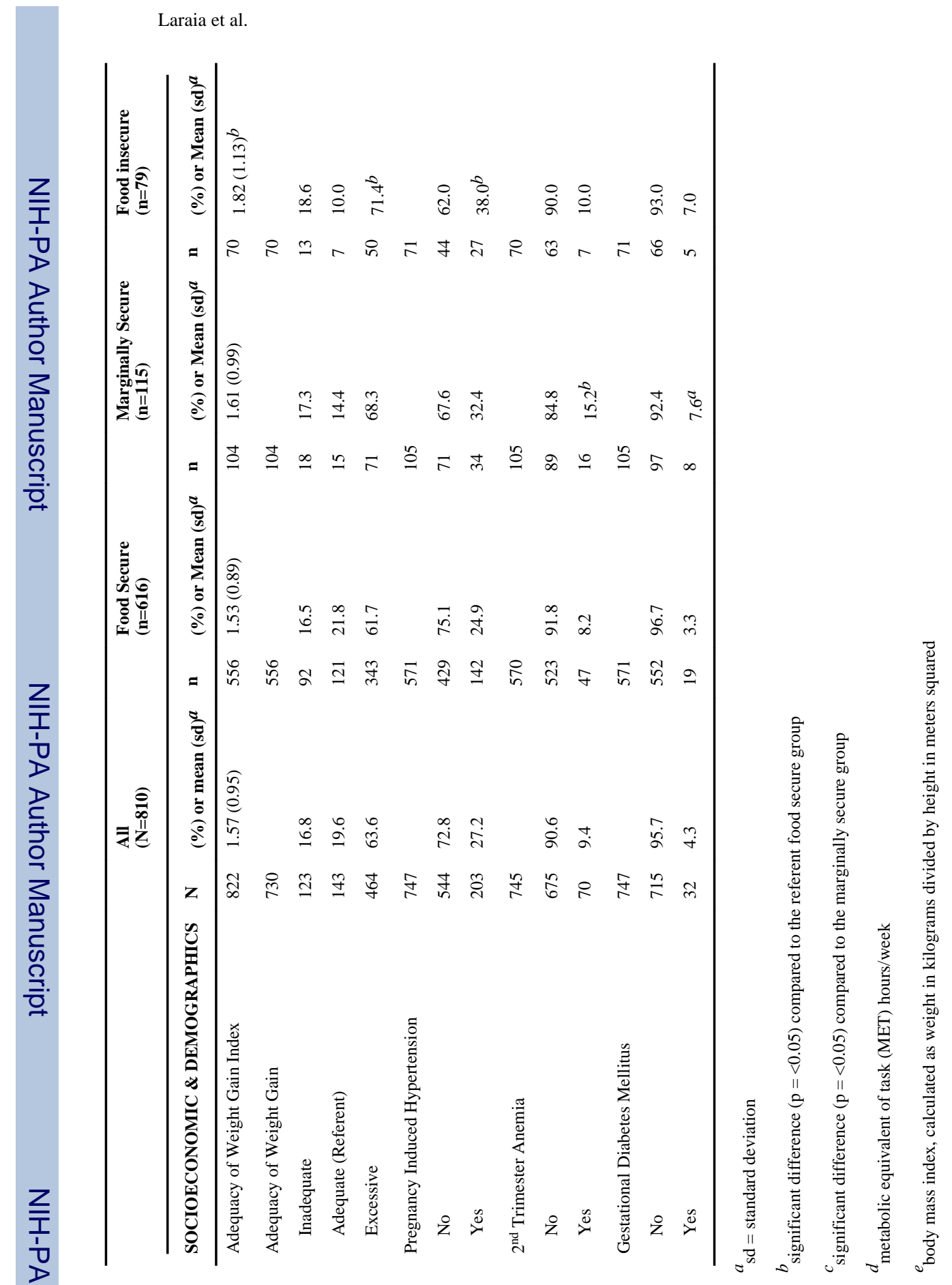




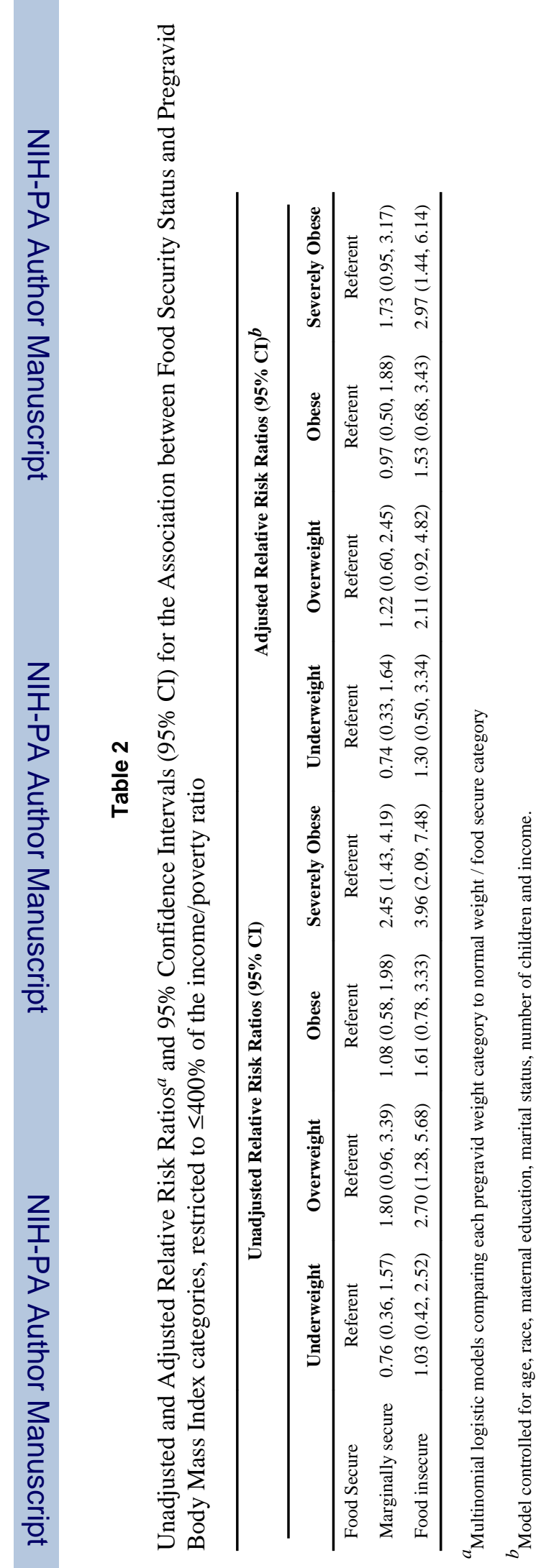




\section{Table 3}

Unadjusted and adjusted $\beta$ coefficient and 95\% confidence intervals (95\% CI) for the association between household food security status and gestational weight gain and adequacy of weight gain ratio, restricted to $\leq 400 \%$ of income/poverty ratio

\begin{tabular}{lcccc}
\hline & \multicolumn{2}{c}{ Gestational weight gain $(\mathbf{k g}) \boldsymbol{a}^{\boldsymbol{a}}$} & \multicolumn{2}{c}{ Adequacy of weight gain ratio } \\
\hline $\begin{array}{l}\beta(95 \% \mathrm{CI}) \\
(\mathrm{n}=747)\end{array}$ & $\begin{array}{c}\text { adjusted } \beta^{b}(95 \% \mathrm{CI}) \\
(\mathrm{n}=673)\end{array}$ & $\beta(95 \% \mathrm{CI})$ & adjusted $\beta^{c}(95 \% \mathrm{CI})$ \\
& & & & $(\mathrm{n}=730)$ \\
Food Secure & Referent & Referent & Referent & Referent \\
Marginally Secure & $0.18(-1.17,1.53)$ & $0.22(-1.26,1.70)$ & $0.08(-0.11,0.28)$ & $0.04(-0.16,0.24)$ \\
Food insecure & $1.48(-0.13,3.08)$ & $1.87(0.13,3.62)$ & $0.28(0.05,0.52)$ & $0.25(0.01,0.49)$ \\
\hline
\end{tabular}

$a_{\text {Kilograms }}=\mathrm{kg}$

${ }^{b}$ Adjusted for pregravid body mass index, gestational age, age, education, race/ethnicity, marital status, number of children, income, number of cigarettes smoked and physical activity

${ }^{c}$ Adjusted for pregravid body mass index, age, education, race/ethnicity, marital status, number of children, income, smoking and physical activity 


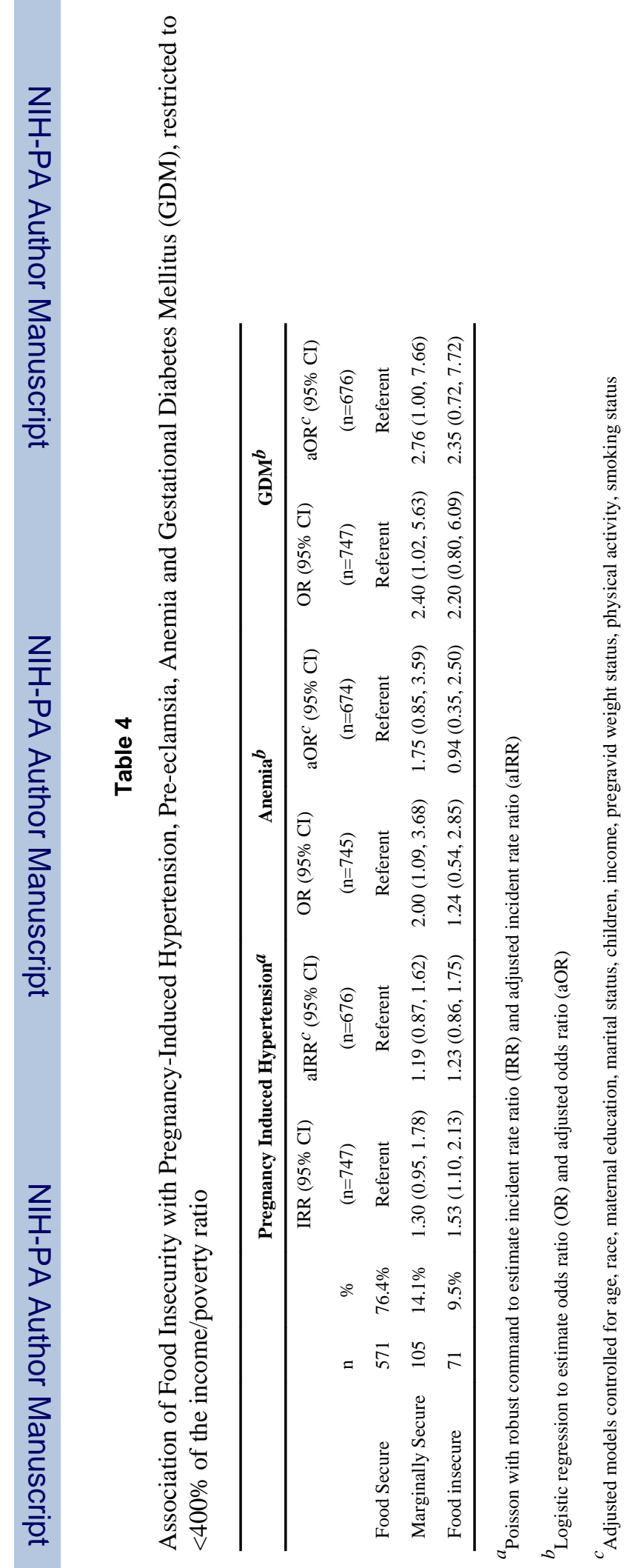

